\title{
Integrating climate change adaptation in coastal governance of the Barcelona metropolitan area
}

\author{
Inga J. Sauer ${ }^{1,2}$ D Elisabet Roca ${ }^{3}$ [D $\cdot$ Míriam Villares $^{3}$ (D)
}

Received: 30 January 2020 / Accepted: 27 April 2021 / Published online: 19 May 2021

(c) The Author(s) 2021

\begin{abstract}
Coastal cities are exposed to high risks due to climate change, as they are potentially affected by both rising sea levels and increasingly intense and frequent coastal storms. Socio-economic drivers also increase exposure to natural hazards, accelerate environmental degradation, and require adaptive governance structures to moderate negative impacts. Here, we use a social network analysis (SNA) combined with further qualitative information to identify barriers and enablers of adaptive governance in the Barcelona metropolitan area. By analyzing how climate change adaptation is mainstreamed between different administrative scales as well as different societal actors, we can determine the governance structures and external conditions that hamper or foster strategical adaptation plans from being used as operational adaptation tools. We identify a diverse set of stakeholders acting at different administrative levels (local to national), in public administration, science, civil society, and the tourism economy. The metropolitan administration acts as an important bridging organization by promoting climate change adaptation to different interest groups and by passing knowledge between actors. Nonetheless, national adaptation planning fails to take into account local experiences in coastal protection, which leads to an ineffective science policy interaction and limits adaptive management and learning opportunities. Overcoming this is difficult, however, as the effectiveness of local adaptation strategies in the Barcelona metropolitan area is very limited due to a strong centralization of power at the national level and a lack of polycentricity. Due to the high touristic pressure, the legal framework is currently oriented to primarily meet the demands of recreational use and tourism, prioritizing these aspects in daily management practice. Therefore, touristic and economic activities need to be aligned to adaptation efforts, to convert them from barriers into drivers for adaptation action. Our work strongly suggests that more effectively embedding adaptation planning and action into existing legal structures of coastal management would allow strategic adaptation plans to be an effective operational tool for local coastal governance.
\end{abstract}

Keywords Adaptive governance $\cdot$ Coastal hazards $\cdot$ Climate change adaptation $\cdot$ Social network analysis $\cdot$ Stakeholders $\cdot$ Barcelona metropolitan area

Inga J. Sauer

inga.sauer@pik-potsdam.de

Extended author information available on the last page of the article 


\section{Introduction}

Coastal cities have an increased need to adapt to the effects of climate change, as they are threatened not only by slow-onset risks such as sea level rise (SLR), but also by severe effects of extreme events that are aggravated by SLR (Wahl et al. 2015; Hallegatte et al. 2013). Analyzing the development of mitigation and adaptation plans in European cities, Reckien et al. (2015) found that proximity to coast and aspects such as unemployment rates, warmer summers, and increased exposure to projected future climate impacts inhibit climate action planning, while membership of climate networks, population size, GDP per capita, and adaptive capacity are positively correlated with adaptation action. In the Mediterranean coast, increasing population trends and tourism pressures intensify exposure to these risks, imposing high demands on governance (Neumann et al. 2015).

Adaptation is commonly defined as "the process of adjustment to actual or expected climate and its effects" (IPCC 2014), where adjustment implies vulnerability reduction, and increasing adaptive capacity - in other words, the ability to impede or moderate damages and to cope with consequences (Aguiar et al. 2018). A study on adaptation plans in developed nations shows that adaptation gaps exist, as adaptation plans are often critically underdeveloped (Preston et al. 2011). On the other hand, there is ongoing progress to improve planned adaptation, and there is some evidence that concrete policy instruments are being introduced and measures are being implemented at least in highly developed countries (Lesnikowski et al. 2016). However, cross-scale studies have shown that adaptation policies are relatively recent and spatially unevenly distributed, especially with a weak local government-led action in areas with lower adaptation capacity, high vulnerability, and exposure (Olazabal et al. 2019), requiring a full consideration of climate risks and scenarios and a much better understanding of policy implications of adaptation tools.

Local governments, and those of cities in particular, have been identified as key agents when it comes to climate change action, while they are especially vulnerable to climate change (IPCC 2007) and often innovative and proactive at the same time (Rosenzweig et al. 2010). The importance and advantages of local community-based adaptation have been highlighted both in science and policy (Fuhr et al. 2018), as local authorities are in the best position to effectively integrate different sectors concerning land use regulations, infrastructure, and local stakeholders from business and civil society (Aguiar et al. 2018). Nonetheless, consideration of adaptation as a local issue falls short, as local governance systems are usually connected to higher administrative scales, e.g., global policy networks, global markets, and supply chains (Atteridge and Remling 2018; Young et al. 2006).

Coastal urban areas are particularly complex and require more collaborative governance structures in order to cope with uncertainty, shocks, and surprises under changing social and biophysical conditions, such as climate change risks (Crona and Hubacek 2010; Chaffin et al. 2016; Folke et al. 2005). Studies on more collaborative approaches, such as adaptive management (Holling 1978), adaptive co-management (Olsson et al. 2004), and adaptive governance (Folke et al. 2005), suggest that engagement of diverse actors and stakeholders is more likely to establish adaptive processes than other systems (Sabatier et al. 2005). Here, we focus on adaptive governance that goes a step further and encompasses the social and institutional conditions that frame the diverse learning environment (Chaffin et al. 2014; Chaffin and Gunderson 2016).

Adaptive governance systems can be described as self-organizing social networks that connect individuals, organizations, and institutions from different administrative layers and actor groups, whereby key actors provide leadership and trust (Folke et al. 2005). In these 
systems, information and knowledge are shared for the development of a common understanding, which fosters social capital and permits social learning. Social capital describes the relationships of trust, their reciprocity, the information exchange between actors, and the evolution of common rules that determine the network dynamics (Adger 2003). Especially, as environmental decisions are often a trade-off between differing interests, it is critical to build and maintain relationships of trust between different actors in resource management and adaptation planning, as these relationships allow wicked problems and various conflicts between the actors to be avoided or solved (Dietz et al. 2003).

Adaptive networks are shaped both by formal institutions, which are defined by laws, and official mandates, which establish the legitimacy of actors and are the basis for guiding actions of individuals and organizations (Pahl-Wostl 2009; Young et al. 2006). Besides these legislative and regulative frameworks, informal policy structures characterized by interactions in networks influence the sharing of both information and knowledge across governance scales and groups of society (Adger 2003; Juhola and Westerhoff 2011). Adaptation develops through different processes, including vertical and horizontal scales of decision-making, and both formal institutions and informal networking contribute to adaptation actions (Juhola and Westerhoff 2011).

In adaptive networks, an efficient coordination of multi-scale actions is crucial to ensure the capacity of local stakeholders to adapt, and a lack of coordination may lead to maladaptation and increased vulnerability (Adger et al. 2005). Multilevel climate risk governance focuses on collective decision-making processes, although it recognizes the influence of individual values and perceptions and the importance of values, culture, and local context in decisions about how to respond to climate change (Corfee-Morlot et al. 2011). As a key characteristic of an adaptive ecosystem governance, poly-centricity implies multiple centers of decision-making that are formally independent from each other yet embedded in an overarching structure that permits cooperative behavior and access to central conflict-solving mechanisms (Folke et al. 2005; Ostrom 2010). Decentralized systems pave the way for social learning, as there can be many units working on similar problems, but effective strategies of central coordination and distribution of information are critical to enable sharing and implementation at higher administrative scales (Huitema et al. 2016; Ostrom 2005).

Climate change adaptation needs to assess both top-down climate impact projections to understand future exposure, and bottom-up knowledge of existing vulnerabilities (Mastrandrea et al. 2010). Therefore, a vivid science-policy relationship is a critical component of adaptive governance networks, which requires adaptive management that describes the science-based process when experiments become policy, and the response of the socio-ecological system must be monitored continuously, to create a closed feedback loop that is essential for social learning and resilience (Gunderson and Light 2006; Pahl-Wostl et al. 2007).

Actions that demarcate the differences and competing authority between scientists and others are described as "boundary work" (Gieryn 1983). Effective boundary work facilitates the integration of climate knowledge into policy decisions at all administrative layers, and in turn aligns research activity to policy needs (Lacey et al. 2018) and reconciles perspectives. Organizations that explicitly focus on mediation work between different disciplines, levels, or scales are known as boundary or bridging organizations (Cash et al. 2006). Bridging organizations are essential for a network's governance capacities, as they (i) improve problem identification and dissemination of knowledge about local context, science, and regulatory communities, (ii) identify feasible and acceptable solutions, and (iii) promote institutional mechanisms to best implement and monitor responses (Vignola et al. 2013).

Political processes are affected not only by scientific institutions, but also by business stakeholders and civil society. In parallel, outcomes of political processes and information exchange 
affect civil society and business stakeholders, in terms not only of legislation and regulation but also of raising awareness, providing transparency, and building trust in policies. Diversity of institutions and knowledge systems is a key requisite for adaptive governance (Gunderson and Light 2006), as mixtures of institutional types (e.g., hierarchies, markets, and community self-governance) can provide an efficient physical, technical, and institutional infrastructure. This allows a variety of rules (and consequently, incentives) to be created, the information supply to be increased, and compliance to be induced (Dietz et al. 2003).

Social network analysis (SNA) has proven useful for mapping governance structures and relationships that are important for collective action for disaster risk reduction, common resource management, and adaptation (Pittman and Armitage 2019; Roca et al. 2018; Therrien et al. 2019). SNA generates proxy measures for node and network characteristics that provide understanding about the actors' capacities to mediate and influence relations (Bodin et al. 2006). Furthermore, they make it possible to evaluate the channels by which civil society, business actors, and policy-makers interact to enable or limit adaptive governance. Networkspecific measures, such as network centrality and density, are only interpretable when they are observed over time or by comparing different networks. In contrast, their significance is very limited for analyzing single networks, and their usefulness as indicators for shifts towards adaptive governance has been questioned even in comparative analysis (Chaffin et al. 2016). On the other hand, node-specific metrics permit different players within a network to be compared, so that centrality characteristics support an assessment of power distribution, boundary-work, stakeholder engagement, and diversity. Furthermore, important insights may help identify the bridging organizations that are responsible for the distribution of information and mediation across scales, domains, and different types of actors (Vignola et al. 2013).

In this work, we apply SNA to map governance structures of coastal risk management in the metropolitan area of Barcelona, taking into account formal as well as informal communication patterns. The SNA visually and quantitatively highlights network connectivity, the diversity of actors, poly-centricity, and the role of single actors, especially the embedding of institutions active in climate change adaptation and scientific institutions. This helps us evaluate the network in terms of suitability for adaptive governance and social learning. We focus on node-specific metrics and use a mixed-methods approach, which permits a wider interpretation of circumstances that lead to given node characteristics and centrality in the network through qualitative information. This allowed us to evaluate the usefulness of these metrics and to identify not only starting points for increasing the likelihood of adaptive governance, but also obstacles to building adaptive capacity that should be overcome (Chaffin et al. 2016). We address (i) how coastal adaptation to climate change is mainstreamed in coastal risk management practices between scales and types of actors; (ii) how prerequisites for adaptive governance, such as science-policy relations, institutional diversity, and poly-centricity, are implemented in the underlying network; and (iii) how these structures either limit or enable adaptive governance.

\section{Case study: Governance of coastal adaptation in the metropolitan area of Barcelona}

\subsection{Study area description}

The case study is limited to the coastal territory of the metropolitan area of Barcelona with 3.2 million inhabitants. Its eight coastal municipalities (from north to south: 
Montgat, Badalona, Sant Adrià del Besos, Barcelona, El Prat del Llobregat, Viladecans, Gava, and Castelldefels) cover $42 \mathrm{~km}$ of coastline (Fig. 1). Of this coastline, $30 \mathrm{~km}$ are beaches, with more than 8 million beach users in the high season. In such an urban development area, recreational activities and tourism are the main functions of these heavily urbanized coastal spaces.

The landscape characteristics of the municipalities north of Barcelona are very different from those in the south, mainly due to the historical differences in land use. The area south of the metropolitan is shared by several distinct activities: highly productive agricultural fields, the protected natural areas of the Delta del Llobregat, and the industrial and logistics activities of the Port of Barcelona and the airport Barcelona-El Prat. In this delta area, there is also a relatively large distance between the urban continuum and the coastline. In contrast, the north is very marked by the tradition of industrial activity, having a compact and very dense urbanization, the presence of marinas that prevent a natural flow of sand, and a railway line built on the old dune line that has completely rigidified the dune-beach system.

Currently, one of the most important problems of metropolitan beaches is coastal regression, which is aggravated by the threats posed by SLR, stronger rainfalls, and storms. The shortage of sand and its (mis-)distribution within the metropolitan coastal zone presents a main challenge of coastal management.

The beaches in the southern area are relatively large and have a certain capacity to recover after storms or other disturbances. Nonetheless, as they are located in deltaic environments, they are greatly threatened by any amount of SLR (Jiménez et al. 2017; Guillen 2008). The beaches in the northern area are narrower than are associated those in the south and are under a stronger sedimentary pressure. Recovering the regulatory and protective

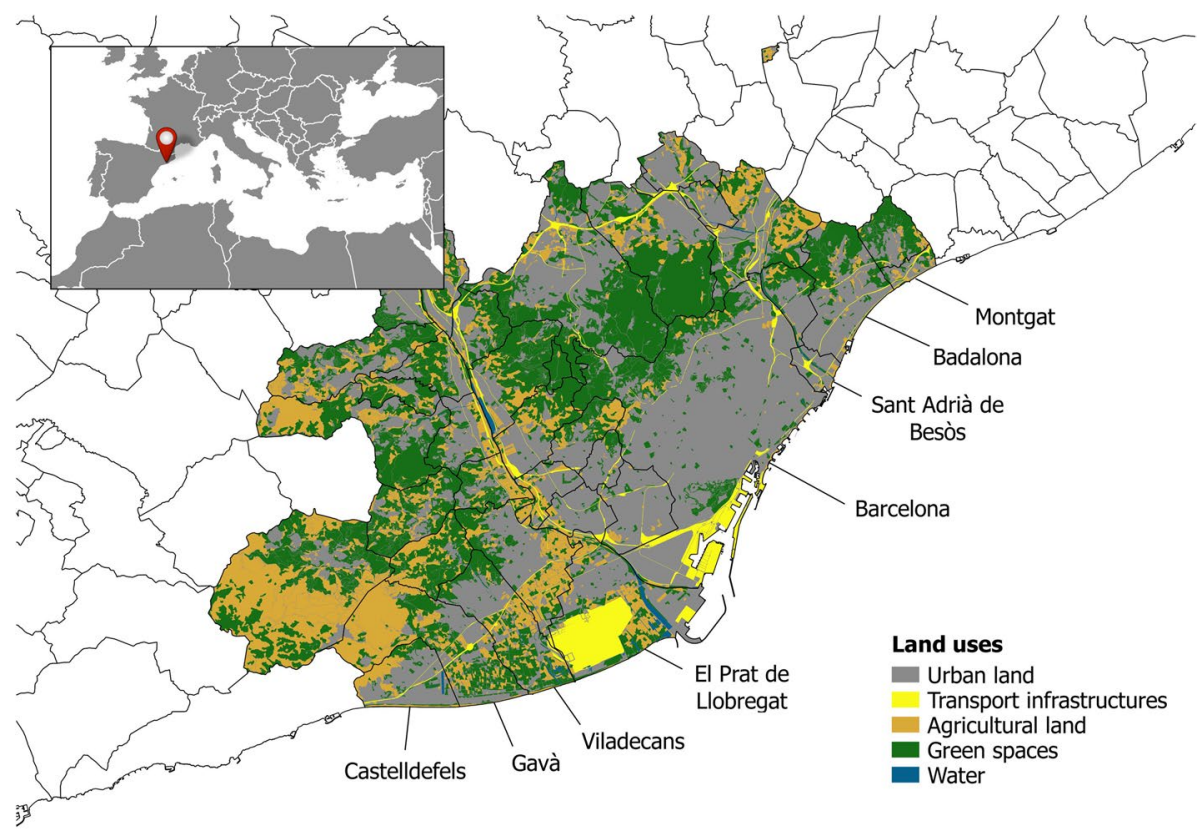

Fig. 1 Coastal area of the Barcelona metropolitan area, showing the eight coastal municipalities and the land use characteristics 
functions of these northern beaches would be very labor intensive (Ballesteros et al. 2018; Jiménez et al. 2017). Taking into account the strong demographic and recreational pressure on this coastline and the great vulnerability associated with the deltas and sandy coasts, implementing climate change adaptation policies is a priority for this coastline.

\subsection{Institutional and policy framework to cope with coastal risks}

Coastal and climate change policies are sectoral policies administered by different institutions, although they depend on the same higher body. The maximum competence in the administration of the coasts of the Spanish state is maintained by the General Directorate of Sustainability of the Coast and the Sea (DG-Coastal; Dirección General de Sostenibilidad de la Costa y del Mar) of the Ministry of Ecological Transition. This institution directs and protects the Public Maritime Terrestrial Domain, which is publicly owned. Law 2/2013, on the Protection and Sustainable Use of the Coastline, which amended Law 22/1988, guarantees its public use, with free accessibility, and aims to preserve the environmental value of the coastline. In the current version of the law, coastal regulation incorporates the vector of climate change for the first time and requires adapting coastal works to the phenomena of regression and the impacts of climate change. Additionally, it sets fixed dates as deadlines for concessions to be modified or to incorporate the measures necessary for adapting to climate change. Despite the clear intentions of the regulation, its implementation still requires specification to be truly effective (Roca and Villares 2016).

The Service of Management of the Littoral (CatCoastal) from the Department of Territory and Sustainability of the Government of Catalonia (GenCat, Generalitat de Catalunya) also publishes the Beach Plans (Plans of Uses and Seasonal Services), which include all authorizations for occupations and activities carried out on the beach. Along the coastal zone of our case study, the Barcelona metropolitan area organization (AMB, Àrea Metropolitana de Barcelona), a supra-local institution between the local and autonomic levels, provides technical support to the municipalities for implementing and managing their Beach Plans.

In relation to climate change policies, the highest state institution is the Spanish Climate Change Office (OECC, Oficina Española del Cambio Climático), created in 2001, which is dependent on the Ministry of Ecological Transition. The first instruments of coastal adaptation approved were the Environment Promotion Plan for Adaptation to Climate Change in Spain (PIMA-Adapta), approved in 2015, and the Coast Adaptation Strategy at Climate Change (EACCC), approved in 2017. These plans, which outline specific projects in vulnerable coastal municipalities, do not take into account any intervention in the metropolitan littoral zone.

At the regional level, the Catalan Climate Change Office (OCCC, Oficina Catalana de Canvi Climàtic) of the GenCat published the "Catalan Strategy for Adaptation to Climate Change (ESCACC) 2013-2020" in 2012. The strategy does not explicitly discuss the coast, as it has a sectoral focus on socio-economic activities. Therefore, while recognizing the need to promote and value dune systems for their protective function, it has a very limited impact on risk management of the coast. In 2017, the OCCC published the Climate Change Law 16/2017, which could have provided the regulatory framework that would require the competent administrations to integrate the climate change variable (Roca and Villares 2016). However, this law aims mainly for mitigation and cannot establish adaptation actions in the coastal area, as the administration of the autonomous region has no competencies over this. 
At the local and metropolitan levels, climate change has been addressed through Local Plans for Adaptation to Climate Change (PLACC), which include measures and actions to prepare municipalities for the consequences of climate change. Currently, this tool is prepared on a voluntary basis by the municipalities, and only 4 of the 8 municipalities of the study area have a PLACC.

Apart from the coastal and climate change adaptation policies that we have mentioned, some institutions also have an impact on the coast. At the regional level, these are the Catalan Agency of Water (ACA, Agència Catalana de l'Aigua), which monitors the quality of bathing water and manages the Public Hydraulic Domain and flood areas; Civil Protection, with powers to develop and deploy general emergency, flood, and water pollution plans; and Port Services, which manages the port infrastructures that are not of regional or local interest. In contrast, the Port of Barcelona, which is of general interest, is the responsibility of the state.

\section{Methods}

A mixed-methods approach was applied in this case study that included both a SNA with quantitative metrics, and a qualitative analysis of semi-structured interviews. Although SNA is useful for gaining insight into the adaptive capacity of a network by using its high diagnostic potential and well-defined metrics (Calliari et al. 2019), the significance of these quantitative indicators remains limited if they are not qualitatively contextualized (Ceddia et al. 2017). Therefore, we have combined it here with a qualitative analysis.

The methodological approach includes the following steps: (i) development of an inventory of representative actors and the limits of the network; (ii) design and application of a semi-structured interview to select actors, to obtain information about their relationships, and to understand their assessment of the current governance system; and finally, (iii) construction of social networks, according to a series of metrics that, complemented by the qualitative information of the interview, provide information about the formal and informal relationships between relevant stakeholders. Here, we discuss their implications in the adaptive governance system and coastal management.

\subsection{Key stakeholders and semi-structured interview}

We first selected an initial inventory of more than one hundred institutions from a review of published literature, covering especially the legal framework summarized in Section 2.2, and the press. From this inventory, we then selected a list of key actors (Table 1) covering the diversity of sectors, territories, and administration levels. These key informants participated in a semi-structured interview, representing a common mixed-methods approach with two objectives (Edwards 2010): (i) to build a database of relationships between actors; and (ii) to characterize, contextualize, and validate relationships. For the actor-relationship database, each participant was given a list of institutions; for each institution on the list, they then had to indicate whether their relationship was continuous, occasional, or nonexistent. Additionally, they had the opportunity to add institutions to the list, if key collaborators were missing. The semi-structured interviews additionally permitted us to collect qualitative information on any and all relationships and collaborations between actors, to correctly interpret quantitative metrics gained through the SNA. Furthermore, the characterization of each relationship was validated by at least two informants. The final inventory 


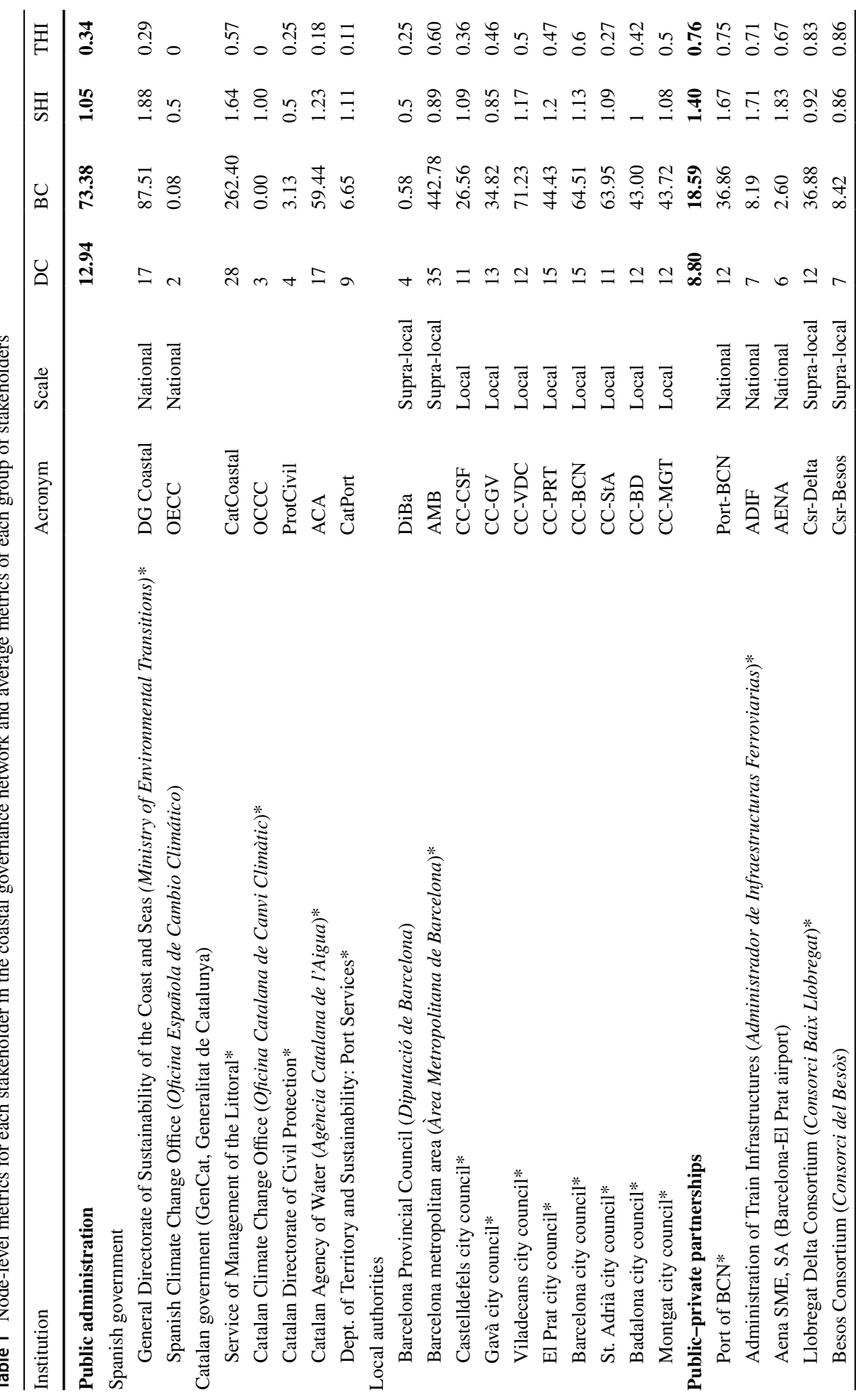




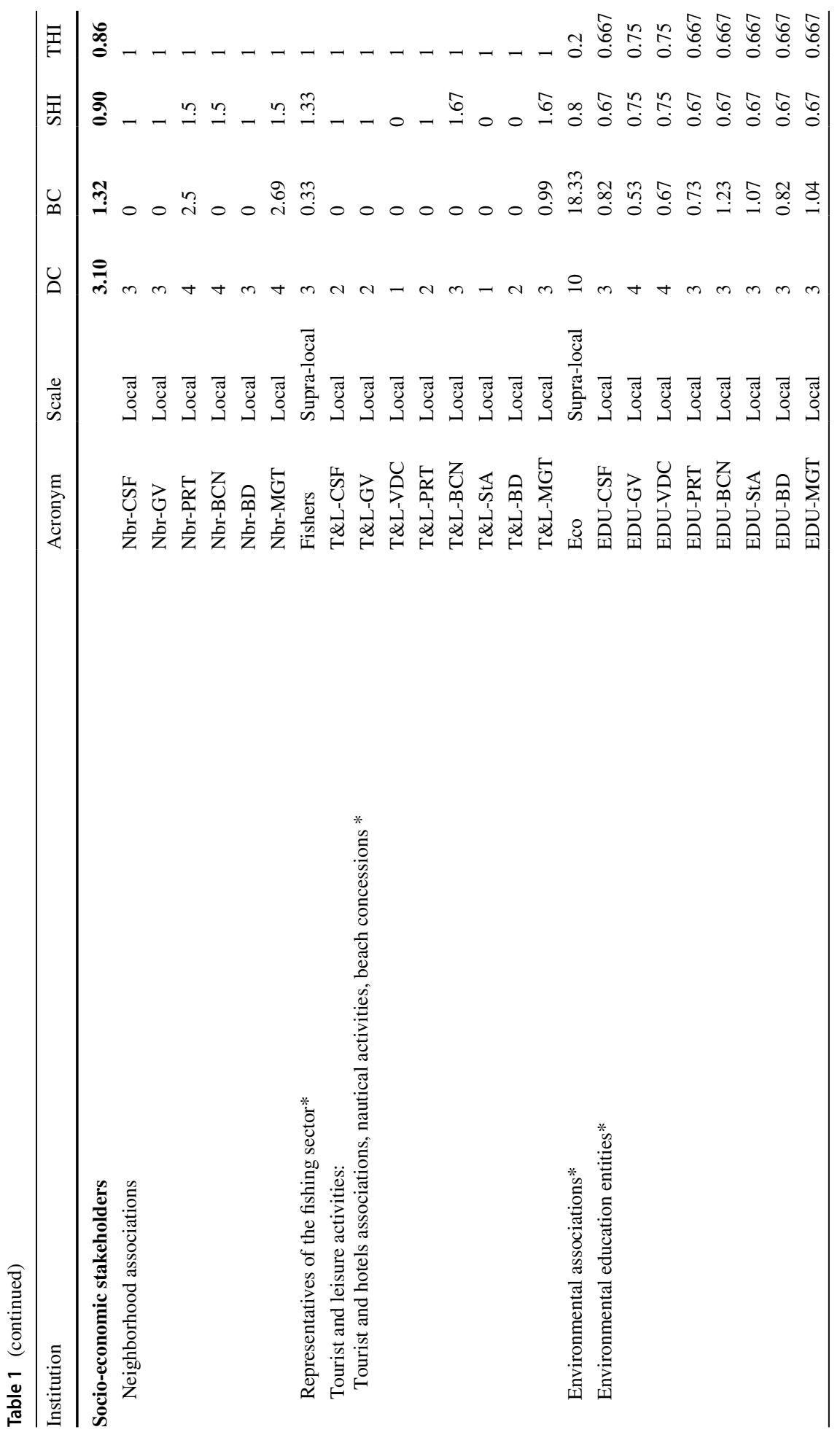




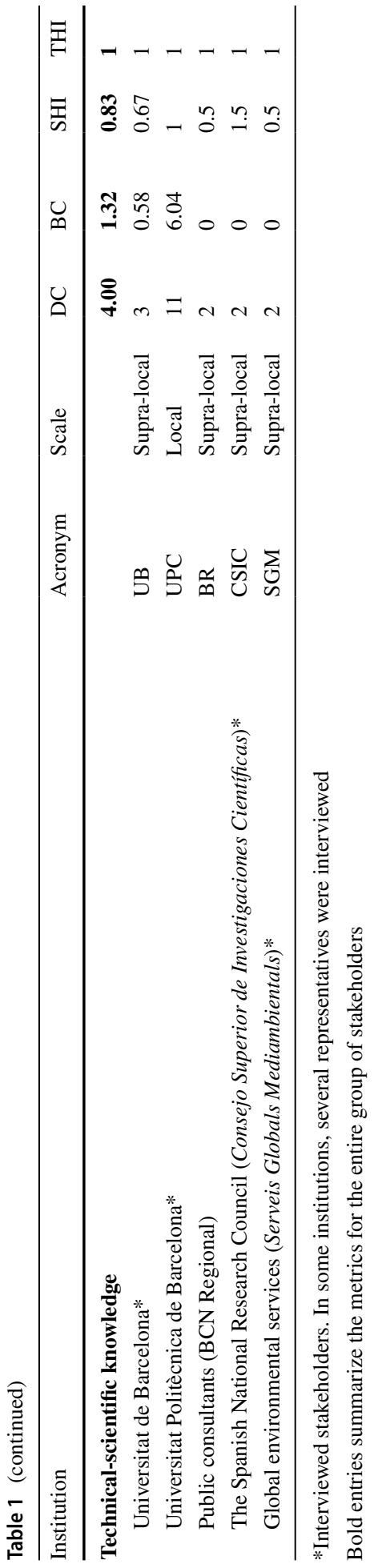


of stakeholders included in the network encompassed 51 actors, 26 of whom were interviewed. Some single actors representing a common interest group, such as neighborhood associations, environmentalists, or educational institutions, were grouped together to get a representative selection of actors and to simplify the construction of the network, its visualization, and its subsequent analysis without losing interpretive quality.

As shown in Table 1, the final list of 51 actors comprised:

- Public administration: The administrative institutions of the different governmental scales (state/regional/metropolitan/municipal);

- Public-private partnerships: Institutions that manage the large transport infrastructures in the area, such as the Port of Barcelona (Port Bcn), the Barcelona-El Prat Airport (AENA), the railway line (ADIF), and the consortia that manage the natural areas of the Delta del Llobregat (Csr-Delta), and the final stretch of the Besos river (CsrBesos).

- Socio-economic stakeholders: Actors representing social interests, such as neighborhood associations of coastal municipalities ("Nbr-X"); those who receive economic performance from coastal resources (such as the tourism sector, catering associations, hospitality, nautical activities, and beach concessionaires) are all grouped under the acronym "T\&L-X" Tourism \& Leisure. Fishermen associations were also incorporated ("Fishers"). The environmental vision contributed by the environmental associations (Environmentalists) and the local network of environmental education entities (Edu-X).

- Technical-scientific knowledge: Three public research centers (UB, UPC, CSIC), a public management consultancy (BR), and a private consultancy (SGM) have been included here.

\subsection{Network construction}

The outcome of each network survey was a list of fluent and occasional relationships of the interviewed stakeholders. As an adequate representation of a network, an adjacency matrix $A$ was constructed, in which the number of columns and lines equals the number of nodes in the network $n$ (whereby each node represents a stakeholder that impacts coastal risk management). For each node (stakeholder) $i$, a link was made by expressing its relationship with the corresponding stakeholder $j$ either with 1 (fluent communication) or 0.5 (occasional communication) or 0 (no communication). Here, all relationships are assumed to be bidirectional; thus, A is a symmetric $n \times n$ matrix, and the diagonal elements are 0 as one actor cannot be related with itself.

$$
\mathrm{A}=\left(\begin{array}{cccc}
0 & 0.5 & 0 & \ldots \\
0.5 & 0 & 1 & \ldots \\
0 & 1 & 0 & \ldots \\
\ldots & \ldots & \ldots & \ldots
\end{array}\right)
$$

Based on the first network and the qualitative information gathered by interviews, a second network was created to visualize collaborations in adaptation planning for climate change. In this network, only institutions that actively participate in adaptation planning or implementation are included as nodes. 


\subsection{Network metrics}

When the structure of a network is known, a variety of useful measures can be calculated to express particular characteristics of the network topology. Here, the focus was on node-level metrics as they are adequate to evaluate the role of specific actors within a network as well as the interactions between different actor types and scales. Furthermore, node-level measures can also be informative for the assessment of adaptive capacity, as they can be proxies for trust, leadership, and social capital (Bodin et al. 2006; Burt 2004).

\subsubsection{Degree centrality}

The degree centrality (DC) of a node is defined as the number of direct neighbors of a node - that is, the number of ties of a node.

$$
D C_{i}=\operatorname{deg}(\mathrm{i})
$$

Within the stakeholder network, each node represents an actor $i$ and the degree can be understood as the number of direct collaborators. Actors with a high degree of centrality are positioned to efficiently mobilize information and resources from the network, enabling a response during times of disturbance and change (Burt 2004; Chaffin et al. 2016).

\subsubsection{Betweenness centrality}

The betweenness centrality measures until which point a node is located along the shortest path between pairs of nodes. It is expressed as the measurement $\mathrm{BC}_{\mathrm{i}}$ for each node, as follows:

$$
B C_{i}=\sum_{s t=1}^{n} n_{s t}^{i}
$$

In formula 2, the expression $n_{s t}^{i}$ is equal to 1 if the node $i$ is located in the shortest path between a node $s$ and a node $t$, and is equal to 0 if there are no paths between $s$ and $t$ or if the node is not located in the shortest path. The betweenness centrality (BC) is a parameter that measures the bridging capacity of an actor to connect other pairs of actors. These bridging organizations synthesize tacit knowledge from subgroups, promoting trust, learning, and innovation (Bodin et al. 2006; Chaffin et al. 2016).

\subsubsection{Type Heterogeneity Index}

To assess the bridging capacity of an actor $i$ between actors of a different type, we introduce the Type Heterogeneity Index (THI). THI $\mathrm{i}_{\mathrm{i}}$ is expressed as the ratio between the number of ties an actor $i$ has with actors of a different type $\left(t_{i} \neq t_{j}\right)$ and its degree (all the ties it has), similar to the area heterogeneity index proposed by Vignola et al. (2013) to assess communication with actors from different policy areas. We use the index $i$ to 
denote a characteristic of the actor we are analyzing, and the index $j$ for characteristics of any other actor.

$$
T H I_{i}=\frac{\sum_{j=0}^{n} a_{i j}^{t_{i} \neq t_{j}}}{\operatorname{deg}(i)}
$$

We introduce this indicator to detect and quantify interdisciplinarity and diversity in the network and to identify key institutions that are moderators between different actor types, disciplines, and priorities.

\subsubsection{Scale Heterogeneity Index}

To investigate bridging capacity across scales of an actor, Vignola et al. (2013) proposed the Scale Heterogeneity Index (SHI) as a ratio between relationships with actors from other administrative scales to the total number of relationships. For this study, this metric is modified by ranking the administrative scales as local $(=0)$, supra-local $(=1)$, regional level $(=2)$, and national $(=3)$, and taking into account the distance in the scale of actors:

$$
S H I_{i}=\frac{\sum_{j=0}^{n} s_{i j}}{\operatorname{deg}(i)}, \text { with } s_{i j}=\left|s_{i}-s_{j}\right|
$$

Actors with a low DHI act and communicate predominantly on the same administrative level, while actors with a high DHI are key for the transfer information and the moderation between different administrative levels.

\subsubsection{Modularity}

In social networks, we often observe community structures, meaning the existence of densely connected subgroups of nodes, with only sparser connections between these subgroups (Fig. 1). These densely connected subgroups (clusters) can be identified through clustering algorithms. Here, we apply a Clauset-Newman-Moore clustering to the risk management network in order to decompose the network into subgroups and identify collaboration clusters (Hu and Liu 2016).

\section{Results}

We have subdivided the results into three subsections. In the first, we describe the general network composition and the positions of actor types within the coastal management network of the metropolitan area of Barcelona. This visualization allows discussing the node characteristics of the most central actors and highlighting the factors that generate centrality to actors within the network. In the second part, we describe how climate change adaptation is mainstreamed in this network and identify promoters of climate change action. Finally, in the third section, we calculate collaboration clusters and identify factors that foster subgroup building. 


\subsection{General network structure and centrality}

Figure 2 shows the network of coastal management in the study area, while Table 1 summarizes the node-specific metrics of all stakeholders and gives a mean value for each group of actors. With respect to the distribution of different actor groups, the core area of the network is mainly represented by institutions of public administration $(\mathrm{DC}=12.94$, $\mathrm{BC}=73.38$ ), which have decision-making power. Located exclusively in the outer periphery $(\mathrm{DC}=3.10, \mathrm{BC}=1.32)$ are socio-economic actors, including groups with economic interests in beach quality for commercial use and safety (such as watersport clubs or beach bar owners), neighborhood associations, environmental organizations, and educational institutions. The public-private corporations that are administrators either of infrastructure, like the airport, railways, and the harbor, or of natural parks close to the first coastal line, can be found mainly in the inner periphery of the network ( $\mathrm{DC}=8.80$, $\mathrm{BC}=18.59)$, while institutions that contribute with scientific or technological expertise can be found both in the inner and the outer periphery $(\mathrm{DC}=4.0, \mathrm{BC}=1.32)$. This

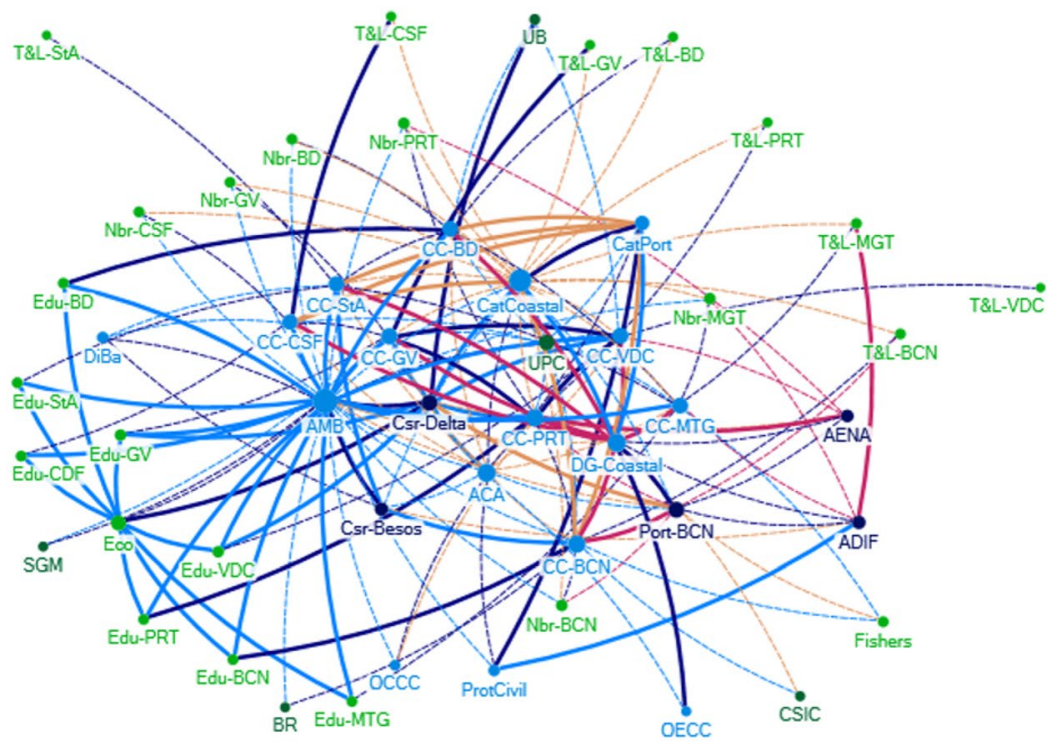

Nodes

Edges

Public Administration

Public-private partnership

Socio-economic stakeholders

Technical scientific knowledge

Scale difference $\left|s_{i}-s_{j}\right|$

Regular communication

Occasional communication

Fig. 2 General network of coastal management in the Barcelona metropolitan area 
network layout reflects to a certain degree what Corfee-Morlot et al. described as three basic layers of decision-making and influence. Specifically, the "core area" of a network is represented by institutions that have formal governmental decision-making power, e.g., governmental administrations including local and city authorities. In contrast, the "inner periphery" encompasses institutions with some degree of autonomy and selfgovernance functions delegated by the state. Finally, the "outer periphery" consists of a wider variety of "suppliers" of information and ideas for policy decisions, and "customers" who are the target audience of decisions. Suppliers and customers include experts, businesses, consumers, and the media and represent the civil-social infrastructure of the public sphere (Corfee-Morlot et al. 2011).

To obtain a deeper understanding of what provides centrality in the underlying social network, we compared the quantitative node-specific metrics (Table 1) with the qualitative information. The analysis revealed different types of centralities within the coastal management network: (i) the centrality associated with legal power and decision-making in the Public Maritime Terrestrial Domain, (ii) the centrality associated with administrative tasks, mainly focused on recreational and tourist use of beaches, and (iii) the centrality based on territorial proximity and provision of technical support.

Centrality based on decision-making power is mainly achieved by the Spanish Central Government through its General Coastal Directorate (DG-Coastal) $(\mathrm{DC}=17, \mathrm{BC}=87.51)$. This reflects the legal framework that exclusively concentrates competencies and decision-making capacity on sediment management, uses in the Maritime-Terrestrial Public Domain, and the authorization to carry out works in a single agency (e.g., DG-Coastal). However, the Catalan government (GenCat), through the Service of Management of the Littoral of Catalonia (CatCoastal), is located more centrally $(\mathrm{DC}=28, \mathrm{BC}=262.40)$. Given its administrative task of managing concessions and authorizations, the GenCat powers are transferred by law. Concessions and authorizations are mainly required to guarantee the touristic and recreational beach use as they are needed, e.g., for beach bars, water sports, and events. Beyond being subject to higher administration, its centrality is based on the relations it maintains with other departments of the autonomous administration, such as water management (ACA), civil protection (ProtCivil), and port administration (Port Bcn), but also on its relations with local actors (such as representatives of nautical activities), although it has little capacity for decision-making about projects and actions in the fields of coastal protection or risk management.

Without legal competences in coastal management, the actor with the highest centrality $(\mathrm{DC}=35, \mathrm{BC}=442.78)$ is the supra-local Barcelona metropolitan area (AMB), mainly because of its role as mediator between different city councils, consultants from science and technology, stakeholders, educational institutions, and other actors from civil society, such as neighborhood associations and environmental organizations. As an institution on a supra-local level, AMB gathers needs and demands of different local authorities in order to solve conflicts, initiate action, and create synergies. This moderating role is also reflected in its high type heterogeneity index $(\mathrm{THI}=0.6)$ compared to other institutions of public administration of equal centrality. Here, its centrality is conferred by its proximity to the municipalities, as its statutory framework constitutes it as an entity that must provide technical and management support to the municipalities of the Barcelona metropolitan area.

The centrality of the municipalities lies primarily in their administrative tasks that have to be coordinated with institutions of higher administrative scales. The primary task is the annual elaboration of the Beach Plans, including all authorizations for occupations and activities carried out on the beach, which need to be approved at the autonomic level (CatCoastal). Besides their management of these recreational and touristic activities, the 
centrality of the City Councils lies in territorial proximity as a contact body for the administration of local infrastructure, civil organizations, and local socio-economic actors.

\subsection{Mainstreaming climate change adaptation}

Notably, the actors responsible for climate change adaptation policies-e.g., the Catalan and the Spanish Offices for Climate Change (OCCC and OECC, respectively) - are in very peripheral positions in the network, with very low centrality metrics $(\mathrm{DC}=3, \mathrm{BC}=0.00$ and $\mathrm{DC}=2, \mathrm{BC}=0.08$, respectively) (Fig. 2). This lack of centrality underscores the lack of integration in coastal management. The low indicators of the management between scales, especially for the Spanish office $(\mathrm{OECC}, \mathrm{SHI}=0.5)$ and also for the Catalan office (OCCC, $\mathrm{SHI}=1.00$ ), indicate that the communication of the offices takes place mainly at their own administrative level. It also suggests that their policies do not affect the local management of the coasts, neither directly nor through mediators. Communication between the OECC and the OCCC is scarce, and the legal competence of these institutions is very limited, especially in coastal management.

Thus, with respect to the climate change adaptation policies and plans within its institutional network, the weak link between the two climate change offices expresses a formal relationship that includes neither effective coordination between the scales, nor a relevant dialogue for coastal management policies in the metropolitan region (Fig. 3). This also highlights the fact that, in terms of coastal management, no relevant interactions take place between the scales of the national and the autonomic governments. This fact was also expressed in the interviews: the policies and plans for climate change adaptation involving the coast are promoted from different administrative levels and have a more reactive than preventive perspective. At the national level, adaptation actions including specific physical measures are promoted within the framework of the EACCC and financed from funds provisioned for the PIMA-Adapta (as explained in Section 2.2). Therein, financial resources are provided for selected municipalities, in order to cover specific measures planned on a national level on coastal protection. As no municipality of the Barcelona metropolitan area is included in this plan, this type of climate adaptation policy initiated on national scale does not reach the local scale in this case study. The PIMA-Adapta is not of operational value, as it does not foresee an incorporation of adaptation politics or a transfer of responsibilities or competencies to lower administrative scales. In Catalonia, climate change mitigation and adaptation policies are established by the OCCC. The Climate Change Law 16/2017 foresees an incorporation of climate change adaptation in the coastal management sector, but due to missing competencies in the DPMT, the law is more of a "recommendation" than obligation to include adaptation measures in the sectoral policies.

The adaptation policies existing at the local and supra-local level, as shown in Fig. 3, are linked to the development of Local Plans for Adaptation to Climate Change (PLACC). The AMB promotes this initiative through its "Plan of Adaptation to Climate Change" (PACC) with the financial support of the OCCC. The AMB umbrella, as seen in Fig. 3, consolidates its role as promoter and provides technical support to local administrations to develop their plans. Despite the broad thematic scope of these plans, the actions related to the coast include a mere inventory of interventions already planned at other administrative levels. This once again highlights the low capacity of action of the municipalities that are bound by an extremely centralized legal framework. Only the Barcelona city council, with its Climate Plan and the Comprehensive Coastline Management Plan (PGIL), has a 


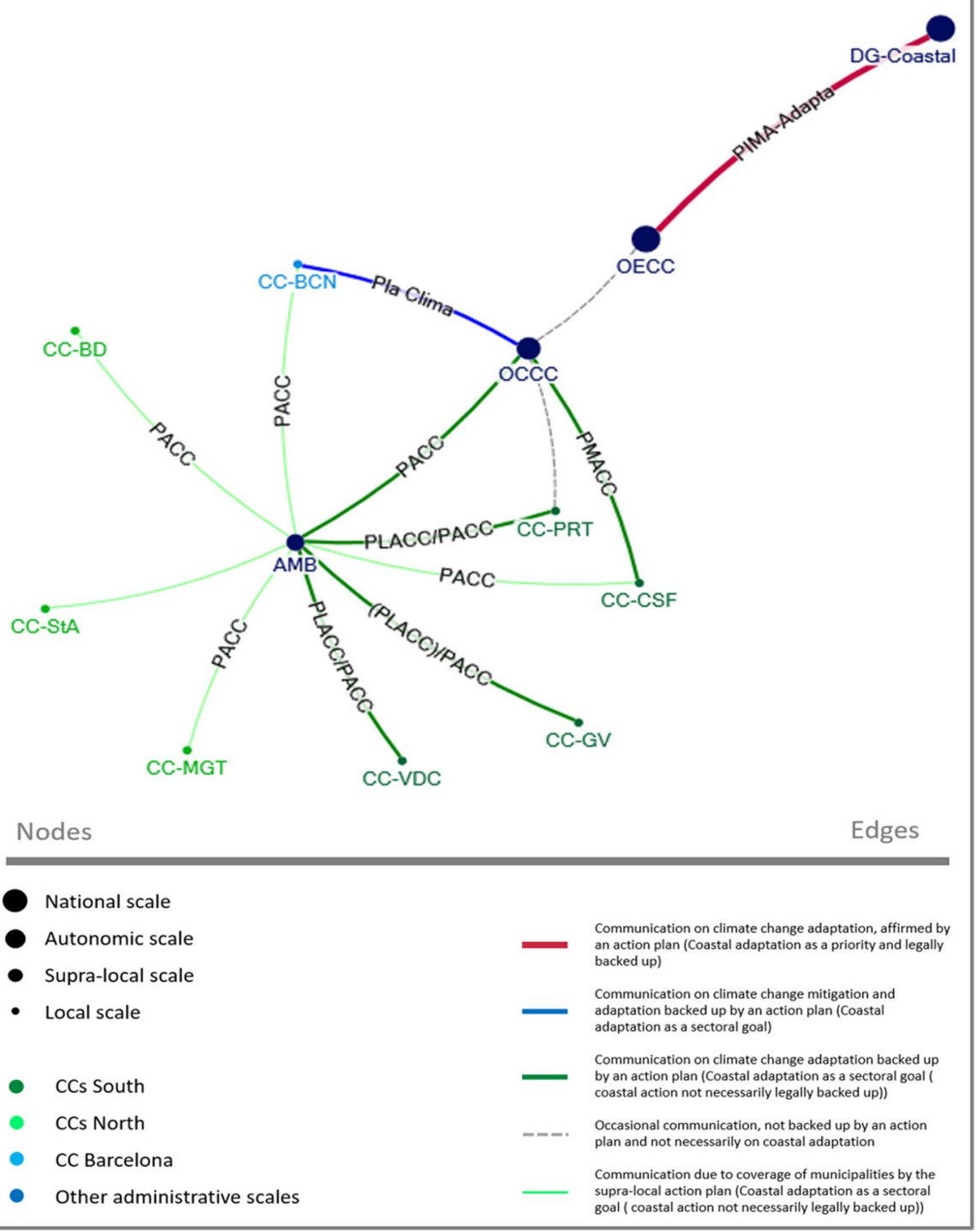

Fig. 3 Network of climate change adaptation policies in the Barcelona metropolitan area and higher administrative levels

framework for dialogue and collaboration between the three administrative levels, with a commission for stable and periodic monitoring over time.

Finally, the Civil Protection agency (ProtCivil) is responsible for giving notice in situations of meteorological events; however, as the responsibility for emergency management falls directly on the city councils, ProtCivil plays a very peripheral position in coastal management $(\mathrm{DC}=4, \mathrm{BC}=3.13$ ) (Fig. 2). ProtCivil does not enter into the network for adaptation planning, as the adaptation action in the Barcelona metropolitan area has a very strategic character and is not yet operational. 


\subsection{Clusters of collaboration networks}

In order to identify subgroups of collaboration, we applied a Clauset-Newman-Moore clustering algorithm on the coastal management network represented in Fig. 2. The five clusters that were identified are shown in Fig. 4. We can summarize different key aspects that frame collaboration clusters, including (i) geographical proximity and local administration of infrastructure, (ii) natural resource allocation, and (iii) inclusion of civil society.

Geographical proximity is of special importance for the subgroups clusters 1 and 3, which are basically formed by stakeholders from the south (cluster 1) or the north (cluster 3) of the Barcelona metropolitan area. In the south, local actors (municipalities and the entities that manage the Llobregat Delta and the airport) are densely connected and collaborate closely in coastal management and conservation of the natural coastal environment. The presence of institutions related to tourist and leisure activities in almost

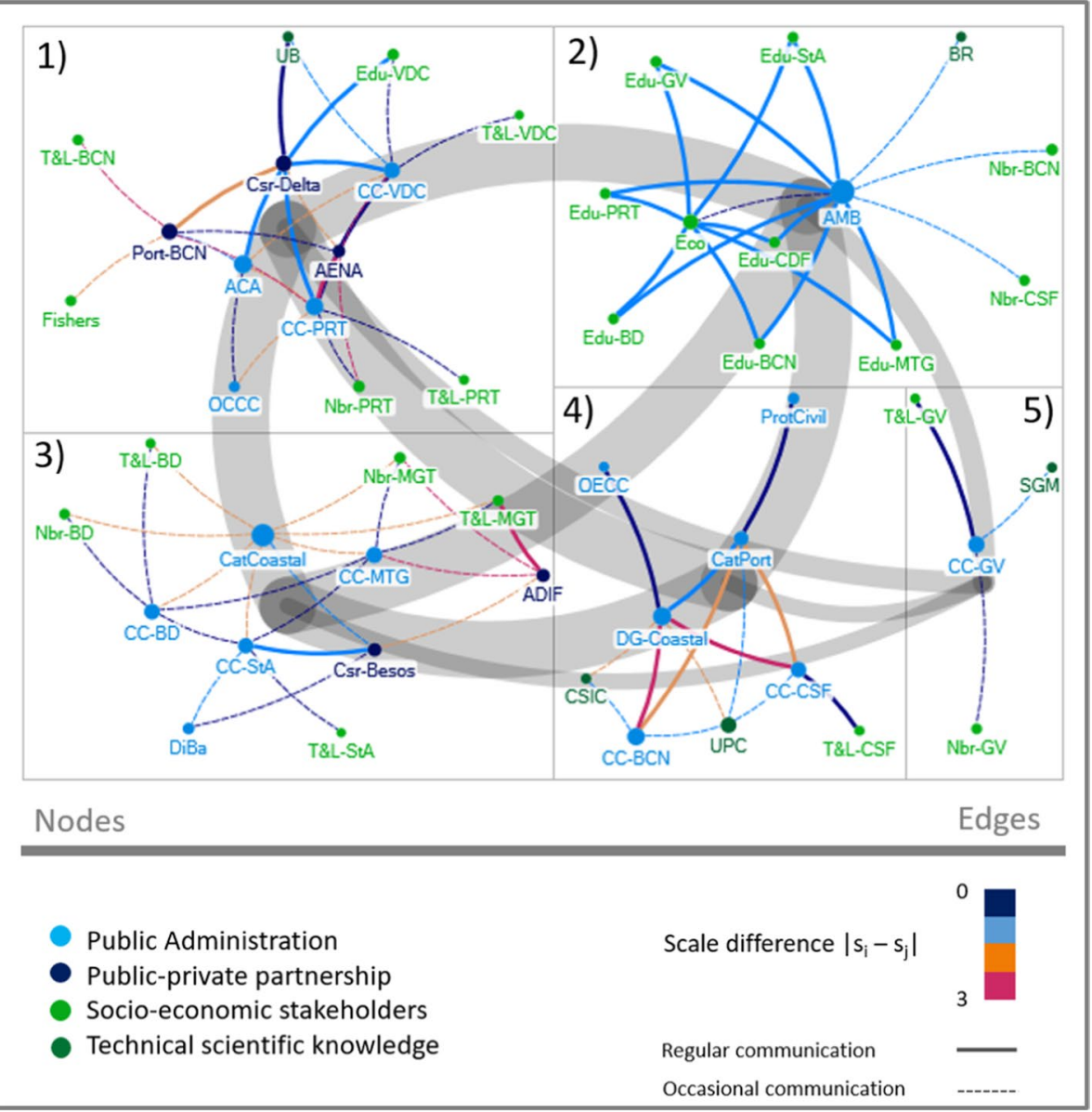

Fig. 4 Clusters found by the Clauset-Newman-Moore algorithm. Gray connections summarize all connections between two clusters in one line 
all clusters (clusters 1, 3, 4, and 5) highlights the importance of the touristic and recreational sector in all areas of collaboration.

In contrast, the northern area is very marked by the industrial use of the past in a phase of transition to a recreational use, with important decontamination tasks. In addition, the presence of a railway infrastructure that runs through the previous dune system requires coordination between the local city council of Montgat (CC-MGT) and the administrator of railway infrastructures (ADIF) (Fig. 4).

The port infrastructure affects the daily management of the coasts both in the municipality of Barcelona and in the southern municipalities. The port presents a large barrier for the natural exchange of sand from the north to the south through the current, and the north sand accumulates in the port structures. This sand must be mechanically distributed to the coastline of the south, provided for in the Environmental Impact Statement of the Port. Due to this problem, the port is connected to the city council of El Prat (CCPRT) and other local authorities in the south (Fig. 4, cluster 1). In general, the beaches to the south of the port are in better environmental conditions, with areas of reconstructed dunes and greater widths, as the result of the dynamics of a protected delta and the collaboration of local administrations with the port. The historical coexistence of uses that have a low compatibility has forced a collaboration between all its representatives. Climate change adaptation policies are taken on mainly by city councils from the southern part of Barcelona (Fig. 3). The higher priority of climate change adaptation is likely to be rooted in the fact that climate change is primarily considered by most stakeholders to be an environmental problem and there is a stronger focus on environmental issues. Furthermore, the natural beaches in the area of the fragile southern river delta have been strongly impacted by coastal floods and storm events, while the northern delta was mainly surrounded by solid infrastructure and has only recently entered a transition phase for recreational use and re-naturalization.

The qualitative analysis suggests that many municipalities require a higher quality of communication with DG-Coastal, as a great institutional distance is often perceived. Collaboration is closer only in the municipality of Barcelona, thanks to the Comprehensive Coastal Management Plan (PGIL) that facilitates and intensifies communication between the head of the DPMT, the Generalitat, and the local administration. In its monitoring commissions, the PGIL addresses issues such as the Beach Plan or sediment management, thereby improving dialogue and collaboration between administrations without implying a change in the distribution of competencies. These institutional proximity differences are partially reflected in the clusters, as Barcelona and DG-Coastal are in the same cluster 4. Therefore, depending on a collaboration table or a Coastal Partnership type participation scheme can facilitate this institutional proximity, as seen in other cases (Stojanovic and Barker 2008). Finally, cluster 2 reflects once again the position of AMB as a connecting factor of the formal coastal governance network and civil society, as it is the center of a cluster consisting of environmental groups, educational institutions, and other citizen organizations.

\section{Discussion}

Here, we discuss how the underlying policy network meets the key requisites of adaptive governance networks in terms of institutional and knowledge diversity, adaptive management, and science-policy interactions, as well as poly-centricity and nesting. We 
explicitly address the role of the bridging organizations and the integration of climate change adaptation policies.

\subsection{Institutional and knowledge diversity}

The network of coastal management in general brings together a variety of different stakeholders and interest groups. The coastal metropolitan area is exposed to intensive recreational use and a competitive touristic market. The importance of the sector, which already becomes visible in the legal framework, is clearly reflected in the network analysis, as the administrative tasks focused on recreational and touristic use are one of the major aspects that brings centrality into the governance network (Section 4.1). In most collaboration clusters, institutions related to tourism and leisure activities are integrated (Section 4.3), revealing that tourism management is a priority within the governance network. Besides the touristic sector, further economy-related factors, such as fishing activities and infrastructure for trade and transport, depend on coastal management. Resource management in terms of sand distribution and beach maintenance is shifted to being a main focal point due to demands of tourism acting as a driver for beach maintenance; on the other hand, touristic administration gains importance in the network, as it is one of the aspects that contributes to centrality and includes most of the business stakeholders.

We also highlight that there is very little diversity in the network on climate change adaptation (Fig. 3). Namely, all institutions included are actors of public administration. Thus, knowledge diversity as a prerequisite for adaptive governance (Chaffin et al. 2014; Dietz et al. 2003) is absent in the adaptation network. The lack of integration of other organization types into climate change adaptation could be rooted in the limited scope of action for these institutions, as decision-making and power over coastal protection are concentrated at a national level. It could however also reflect a lack of both public awareness and information. In other words, a lack of diversity in climate change adaptation planning suggests that risks are not effectively communicated within the network. Environmental organizations and other institutions from civil society are not actively participating in coastal adaptation action. Neighborhood engagement exists in terms of local links between neighborhood associations and city councils (Fig. 2), but it is usually more linked to touristic activity and administrative offence than to coastal protection. Linkages of environmental organizations (see Fig. 2) are based more on communication about biodiversity aspects and environmental education than on environmental and climate change risks. The great variety of stakeholders brings together various interests in the coastal ecosystem, but the need for coastal protection and adaptation does not reach their agendas, indicating a lack of reciprocity that is however necessary to foster social capital (Adger 2003).

We identified the Barcelona supra-local administration (AMB) as an important bridging organization between different actor types (Fig. 4). It is in a key position to increase knowledge diversity within the adaptation network and to disseminate the importance of climate change adaptation to civil society and businesses, especially in terms of awareness rising and provision of knowledge and information (Vignola et al. 2013). Currently, however, it acts instead as a receptor, gathering and communicating needs of diverse stakeholders; importantly, active dissemination of adaptation and protection needs is still missing. On the other hand, intervention by socio-economic stakeholders will remain limited due to hierarchical institutions that are predominant in this governance network. Adaptation actions take place autonomously (Fig. 3), are self-organized (which is a desired factor in adaptive 
ecosystem governance), and can be observed as an emergent phenomenon. Yet, the effectiveness of adaptation action is very limited due to a strong centralization of power. The additional market institutions raised by tourism do not support a more adaptive structure, as they foster short-term thinking and shift the focus of hierarchical institutions (e.g., the legal framework and delegation of competences) to mere beach administration.

\subsection{Science-policy interactions and institutional learning}

Social learning by means of well-designed feedback loops is a first step on the way to adaptive governance (Chaffin and Gunderson 2016). In the underlying network of coastal management, the scientific institutions and consultancies are mostly located in the outer periphery and are connected via the AMB. The only exception is one academic institution, the UPC (Fig. 2), which has a role as a reference institute in investigations of coastal risks at the Catalan level. However, in terms of coastal management and protection, this institution acts as the only relevant scientific consultant within network boundaries. Notably, the DGCoastal bases its scientific evaluation for adaptation planning on scientific stakeholders from outside the case study area, so that none of the local scientific consultants is directly integrated into the network of climate change adaptation (Fig. 3). The increased centrality of the academic institution (UPC) in the network of coastal management (Fig. 2) can be well interpreted as an indicator of trust, as local administrations ask for expert judgement on their own initiative, although communication is occasional and effective monitoring is likely missing. More diverse science communication would permit a wider set of possible experiments in adaptation measures and increase knowledge diversity. Decoupling the scientific consultants in terms of adaptation and coastal protection impedes closed feedback loops for evaluating the effectiveness of adaptation options and coastal protection measures, which is a clear constraint to effective adaptive governance. Local expertise gained from coastal protection actions is not directly communicated to scientific consultants at the higher administrative levels, who are responsible for vulnerability assessments for national adaptation planning. This lack of multi-scale coordination limits effective adaptive management and learning opportunities, as knowledge should be continuously updated and adjusted, and each management action should be viewed as an opportunity to gain experiences on how to adapt to changing conditions (Carpenter and Gunderson 2001; Folke et al. 2005). Furthermore, the Spanish and Catalan agencies responsible for climate change (the OECC and OCCC, respectively) are not connected to supra-local or local scientific institutions (Fig. 2), which limits the uptake of local scientific management experiences and their integration in climate change policies.

\subsection{Poly-centricity and cross-scale interactions}

In this work, we have identified a lack of vertical coordination and a mismatch between adaptation actions coming from different administrative layers, which is a known common constraint in adaptation planning (IPCC 2014). As an adaptation action initiated by the Spanish Climate Change Office, which is legally backed up and funded, does not encompass action in the case study area and does not confer power or responsibility to actors from lower administrative scales, there is no legally backed up adaptation action in the study area. On the other hand, we can see that a supra-local bridging organization (AMB) acts as an important promoter of adaptation action and has established cross-scale relationships between stakeholders. The local adaptation plans are a promising instrument, as they 
give an overview of risks and ongoing and planned actions in many sectors. In the case of coastal adaptation, they summarize ongoing or foreseen coastal protection measures, yet they were not framed in the wider context of climate change adaptation. We can observe similar tendencies as Preston and colleagues (Preston et al. 2011), who find that management plans that are based specifically on climate change adaptation, rather than on integrating climate change into the range of existing policies and environmental management efforts, often serve as a tool for demonstrating action on climate change. However, there is little scope of action for the initiators of the local adaptation plans, as they cannot plan interventions in coastal areas. Nevertheless, efforts on soft measures, including early warning systems and emergency plans for fast-onset events (such as storms), or raising awareness for both fast- and slow-onset risks (such as sea-level rise), could be improved. Also in this context, the AMB is in a promising position as a bridging organization between science, civil society, and the public administration.

While the Catalan Climate Change Agency is directly involved in climate change adaptation in the study area (Fig. 3), the leading position within the movement is instead attributed to the supra-local mediator of the metropolitan region (AMB). This situation (as exemplified in Fig. 2) opens a debate about the necessity and effectiveness of creating new offices that should be responsible for the adaptation and mitigation of climate change, and confirms that the formation of overarching institutions does not necessarily ensure robust adaptation (Preston et al. 2011). The exclusion of these agencies, which is clearly visible in all their node-level metrics, suggests that climate change adaptation is not successfully nested in the system, which greatly limits adaptation possibilities (Dietz et al. 2003; Lyle 2015).

Geographic proximity is the main driver for building subgroups, due to the communication on infrastructure, as is clearly visible in Fig. 4. The city councils are the major hubs in their sub-groups, connecting coastal administration from higher administrative scales, and they have reasonably high BCs and average SHI scores, as they have both direct connections to high administrative scales and different actor types at their local scale. It is striking that adaptation activity is more pronounced in the southern coastal area of the metropolitan region, where environmental protection already is a bigger issue, as the coastal area is in a more natural state as compared to other parts of the metropolitan area. Thus, the natural environment could act as a driver for climate action, as climate change is often perceived as a pure environmental problem.

Although we observe formation of subgroups, there is no real poly-centricity in the network. This is observed by the fact that the subgroups and the civil councils (as their hubs) are not at all formally independent, as power is very concentrated at the national level. We also would like to argue that continuous communication and centrality are not necessarily an indicator of trust and collaboration, but can also reflect a mere legislative obligation. The centrality of the bridging organization is not at all related to formal power on coastal protection, but is rather based on gathering demands, while the centrality of the Catalan Service of Management of the Littoral (CatCoastal) is due to conferred competencies that are purely linked to touristic activities and are not relevant for decisions about coastal protection. A systematic approach to consider hierarchies and reciprocities in SNA would therefore be more adequate to improve the significance of quantitative indicators in future studies. It has to be highlighted that although the AMB has limited formal power, it acts as a promoter of adaptation policies, with an increasing number of city councils participating in the plans. 


\subsection{Global policy implications}

The case study allows us to provide suggestions to foster the implementation of climate change adaptation policies in coastal areas that may be valuable beyond the scope of this case study.

Adaptation action is initiated and promoted at the local scale; however, this action needs to be legally backed up and supported by higher administrative layers to become of operational use. The creation of new institutions responsible for the promotion of climate change mitigation and adaptation action, but without legal scope of action in coastal policies, is a shortcoming, as the institutions are not integrated into the sector specific governance system. Notably, on the global scale, local adaptation plans have been found to be often more concrete than national strategies (Olazabal et al. 2019). The local adaptation plans that are the major outcome of adaptation action in this case study are strategic rather than operational (e.g., they do not include concrete emergency plans). The integration of concrete actions in local adaptation plans is constrained by the lack of legal competence of local administration in the coastline. Our study clearly reveals that efficient cross-scale interaction is necessary to permit the elaboration of operational plans and to turn strategies into action. All in all, our work strongly supports the integration of climate change adaptation policies into existing legal structures and institutions of relevant sectors, and creating national adaptation plans that specifically address the propagation of adaptation action from higher to lower, as well as lower to higher, administrative scales.

Demands of recreational use and tourism, and prioritizing these in daily communication, did not lead in this case to investments in long-term adaptation efforts, which are however needed to reduce the effects of climate change. The legal framework is oriented to primarily meet these demands, fostering short-term thinking and reactive actions, which is known as a common social barrier to adaptation (Biesbroek et al. 2011). Also, on a larger scale, coastal governance in tourist destinations has been found to be often limited and hampered by economic interests and unequal power relations (Gössling et al. 2017). Therefore, more efforts are necessary to efficiently align adaptation action with tourism and economic activity, to turn them into drivers for adaptation action. Promising opportunities are for instance the implementation of nature-based solutions (NBS) for coastal adaptation (Saleh and Weinstein 2016; Narayan et al. 2017; Nguyen 2018), which are in general wellaccepted and often even financially supported by tourists (Sauer et al. 2019).

\section{Conclusions}

We applied a mixed-methods approach that includes SNA and a wider qualitative analysis in order to evaluate how adaptive governance and climate change adaptation mainstreaming is hampered or enabled in the coastal management network of the metropolitan area of Barcelona. We find a mismatch between adaptation actions from different administrative layers, and thus a constraining cross-scale interaction. While physical protection measures for coastal protection require legitimization from the national scale, the adaptation action is mainly promoted at a supra-local level; nonetheless, we found no efforts from the national administration to take up or support adaptation action initiated at the local scale. Furthermore, even though diverse stakeholders are present in the network, this aspect alone does not lead to productive institutional diversity, as reciprocity is often missing and needs and risks are not efficiently dissimilated. We can identify institutional diversity to a certain degree as hierarchical, formal institutions, market institutions coming from tourism, 
and self-organization groups with a limited scope of action. Self-organization emerges for instance from climate change adaptation planning by diverse municipalities, yet it has remained ineffective to date as it has no legal backing, while hierarchical institutions are closely linked with tourism management. Our study suggests that adaptation planning and action need to be integrated into existing legal structures of coastal management to convert strategic adaptation plans into an effective operational tool for local coastal governance. While tourism management is an obvious need, due to touristic pressure, it easily gains priority in management practice and shifts attention away from adaptive governance. Our analysis highlights both the importance and the potential that bridging organizations can have, as we can clearly attribute a promoter role to the supra-local administration. Such qualitative analyses are highly relevant for placing quantitative metrics into an adequate context, in order to identify entry points for efficient adaptation policies and a targeted propagation of adaptive action across scales.

Acknowledgements This research was performed in the framework of the M-CoastAdapt project (CTM2017-83655-C2-1-R), funded by the Spanish Ministry of Science and Innovation (MINECO/AEI/ FEDER), the Governance Map of the Metropolitan Area of Barcelona project funded by Àrea Metropolitana de Barcelona and supported by the German Federal Ministry of Education and Research (BMBF) under the research project SLICE (FKZ: 01LA1829A).

Funding Open Access funding enabled and organized by Projekt DEAL.

Open Access This article is licensed under a Creative Commons Attribution 4.0 International License, which permits use, sharing, adaptation, distribution and reproduction in any medium or format, as long as you give appropriate credit to the original author(s) and the source, provide a link to the Creative Commons licence, and indicate if changes were made. The images or other third party material in this article are included in the article's Creative Commons licence, unless indicated otherwise in a credit line to the material. If material is not included in the article's Creative Commons licence and your intended use is not permitted by statutory regulation or exceeds the permitted use, you will need to obtain permission directly from the copyright holder. To view a copy of this licence, visit http://creativecommons.org/licenses/by/4.0/.

\section{References}

Adger WN (2003) Social capital, collective action, and adaptation to climate change. Econ Geogr 79:387404. https://doi.org/10.2307/30032945

Adger WN, Arnell NW, Tompkins EL (2005) Successful adaptation to climate change across scales. Glob Environ Chang 15:77-86. https://doi.org/10.1016/j.gloenvcha.2004.12.005

Aguiar FC, Bentz J, Silva JMN, Fonseca AL, Swart R, Santos FD, Penha-Lopes G (2018) Adaptation to climate change at local level in Europe: an overview. Environ Sci Policy 86:38-63. https://doi.org/10. 1016/J.ENVSCI.2018.04.010

Atteridge A, Remling E (2018) Is adaptation reducing vulnerability or redistributing it? Wiley Interdiscip Rev Clim Chang 9:e500. https://doi.org/10.1002/wcc.500

Ballesteros C, Jiménez JA, Viavattene C (2018) A multi-component flood risk assessment in the Maresme coast (NW Mediterranean). Nat Hazards 90:265-292. https://doi.org/10.1007/s11069-017-3042-9

Biesbroek R, Klostermann J, Termeer C, Kabat P (2011) Barriers to climate change adaptation in the Netherlands. Clim Law https://doi.org/10.3233/CL-2011-033

Bodin Ö, Crona B, Ernstson H (2006) Social networks in natural resource management: what is there to learn from a structural perspective? Ecol Soc 11.https://doi.org/10.5751/ES-01808-1102r02

Burt RS (2004) Structural holes and good ideas. Am j Sociol 110:349-399. https://doi.org/10.1086/421787

Calliari E, Michetti M, Farnia L, Ramieri E (2019) A network approach for moving from planning to implementation in climate change adaptation: evidence from southern Mexico. Environ Sci Policy 93:146157. https://doi.org/10.1016/j.envsci.2018.11.025

Carpenter SR, Gunderson LH (2001) Coping with collapse: ecological and social dynamics in ecosystem management: like flight simulators that train would-be aviators, simple models can be used to evoke 
people's adaptive, forward-thinking behavior, aimed in this instance at sustainability of. Bioscience 51:451-457. https://doi.org/10.1641/0006-3568(2001)051[0451:cwceas]2.0.co;2

Cash DW, Adger WN, Berkes F, Garden P, Lebel L, Olsson P, Pritchard L, Young O (2006) Scale and cross-scale dynamics: governance and information in a multilevel world. Ecol Soc 11.https://doi.org/ 10.5751/es-01759-110208

Ceddia MG, Christopoulos D, Hernandez Y, Zepharovich E (2017) Assessing adaptive capacity through governance networks: the elaboration of the flood risk management plan in Austria. Environ Sci Policy 77:140-146. https://doi.org/10.1016/j.envsci.2017.08.014

Chaffin BC, Gunderson LH (2016) Emergence, institutionalization and renewal: rhythms of adaptive governance in complex social-ecological systems. J Environ Manage. https://doi.org/10.1016/j. jenvman.2015.09.003

Chaffin BC, Gosnell H, Cosens BA (2014) A decade of adaptive governance scholarship: synthesis and future directions. Ecol Soc 19:56. https://doi.org/10.5751/ES-06824-190356

Chaffin BC, Garmestani AS, Gosnell H, Craig RK (2016) Institutional networks and adaptive water governance in the Klamath River Basin, USA. Environ Sci Policy 57:112-121. https://doi.org/10. 1016/j.envsci.2015.11.008

Corfee-Morlot J, Cochran I, Hallegatte S, Teasdale PJ (2011) Multilevel risk governance and urban adaptation policy. Clim Change 104:169-197. https://doi.org/10.1007/s10584-010-9980-9

Crona B, Hubacek K (2010) The right connections: how do social networks lubricate the machinery of natural resource governance? Ecol Soc https://doi.org/10.5751/ES-03731-150418

Dietz T, Ostrom E, Stern PC (2003) The struggle to govern the commons. Science 302:1907-1912. https://doi.org/10.1126/science.1091015

Edwards G (2010) Mixed-method approaches to social network analysis. ESRC Natl Cent Res Methods NCRM.015, 1-30

Folke C, Hahn T, Olsson P, Norberg J (2005) Adaptive governance of social-ecological systems. Annu Rev Environ Resour 30:441-473. https://doi.org/10.1146/annurev.energy.30.050504.144511

Fuhr H, Hickmann T, Kern K (2018) The role of cities in multi-level climate governance: local climate policies and the $1.5^{\circ} \mathrm{C}$ target. Curr Opin Environ Sustain 30:1-6. https://doi.org/10.1016/J. COSUST.2017.10.006

Guillen J (2008) Els riscos litorals a Catalunya. In: Vilaplana JM (Dirs) (ed) Informe RISKAT. Els Riscos naturals a Catalunya. Consell Assessor del Desenvolupament Sostenible. Generalitat de Catalunya, pp 1-26. Available at: http://cads.gencat.cat/web/.content/Documents/Publicacions/els_ riscos_litorals_a_catalunya.pdf

Gieryn TF (1983) Boundary-work and the demarcation of science from non-science: strains and interests in professional ideologies of scientists. Am Sociol Rev 48:781. https://doi.org/10.2307/2095325

Gössling S, Hall CM, Scott D (2017) Coastal and ocean tourism. In: Handbook on marine environment protection. Springer International Publishing, pp. 773-790. https://doi.org/10.1007/978-3-31960156-4_40

Gunderson L, Light SS (2006) Adaptive management and adaptive governance in the everglades ecosystem. Policy Sci 39:323-334. https://doi.org/10.1007/s11077-006-9027-2

Hallegatte S, Green C, Nicholls RJ, Corfee-Morlot J (2013) Future flood losses in major coastal cities. Nat Clim Chang 3:802-806. https://doi.org/10.1038/nclimate1979

Holling CS (1978) Adaptive environmental assessment and management. John Wiley \& Sons

Hu F, Liu Y (2016) A new algorithm CNM-Centrality of detecting communities based on node centrality. Phys A Stat Mech Its Appl 446:138-151. https://doi.org/10.1016/J.PHYSA.2015.10.083

Huitema D, Adger WN, Berkhout F, Massey E, Mazmanian D, Munaretto S, Plummer R, Termeer CCJAM (2016) The governance of adaptation: choices, reasons, and effects. Introduction to the Special Feature. Ecol Soc 21:37. https://doi.org/10.5751/ES-08797-210337

IPCC (2007) Climate Change 2007: impacts, adaptation and vulnerability. In: Parry ML, Canziani OF, Palutikof JP, van der Linden PJ, Hanson CE (eds) Contribution of Working Group II to the Fourth Assessment Report of the Intergovernmental Panel on Climate Change. Cambridge University Press, Cambridge (976pp)

IPCC (2014) Climate change 2014: impacts, adaptation and vulnerability: Part A: global and sectoral aspects: Working Group II contribution to the IPCC Fifth Assessment Report. Cambridge University Press, Cambridge

Jiménez JA, Valdemoro HI, Bosom E et al (2017) Impacts of sea-level rise-induced erosion on the Catalan coast. Reg Environ Change 17:593-603. https://doi.org/10.1007/s10113-016-1052-X

Juhola S, Westerhoff L (2011) Challenges of adaptation to climate change across multiple scales: a case study of network governance in two European countries. Environ Sci Policy 14:239-247. https:// doi.org/10.1016/j.envsci.2010.12.006 
Lacey J, Howden M, Cvitanovic C, Colvin RM (2018) Understanding and managing trust at the climate science-policy interface. Nat Clim Chang 8:22-28. https://doi.org/10.1038/s41558-017-0010-z

Lesnikowski A, Ford J, Biesbroek R, Berrang-Ford L, Heymann SJ (2016) National-level progress on adaptation. Nat Clim Chang 6:261-264. https://doi.org/10.1038/nclimate2863

Lyle G (2015) Understanding the nested, multi-scale, spatial and hierarchical nature of future climate change adaptation decision making in agricultural regions: a narrative literature review. J Rural Stud. https://doi.org/10.1016/j.jrurstud.2014.10.004

Mastrandrea MD, Heller NE, Root TL, Schneider SH (2010) Bridging the gap: linking climate-impacts research with adaptation planning and management. Clim Change 100:87-101. https://doi.org/10. 1007/s10584-010-9827-4

Narayan S, Beck MW, Wilson P, Thomas CJ, Guerrero A, Shepard CC, Reguero BG, Franco G, Ingram JC, Trespalacios D (2017) The value of coastal wetlands for flood damage reduction in the Northeastern USA. Sci Rep 7:9463. https://doi.org/10.1038/s41598-017-09269-Z

Neumann B, Vafeidis AT, Zimmermann J, Nicholls RJ (2015) Future coastal population growth and exposure to sea-level rise and coastal flooding - a global assessment. PLoS ONE 10:e0118571. https://doi.org/10.1371/journal.pone.0118571

Nguyen TP (2018) Melaleuca entrapping microsites as a nature based solution to coastal erosion: a pilot study in Kien Giang. Vietnam Ocean Coast Manag 155:98-103. https://doi.org/10.1016/j.oceco aman.2018.02.005

Olazabal M, Ruiz de Gopegui M, Tompkins EL, Venner K, Smith R (2019) A cross-scale worldwide analysis of coastal adaptation planning. Environ Res Lett 14:124056. https://doi.org/10.1088/17489326/ab5532

Olsson P, Folke C, Berkes F (2004) Adaptive comanagement for building resilience in social-ecological systems. Environ Manage 34:75-90. https://doi.org/10.1007/s00267-003-0101-7

Ostrom, E (2005) Understanding institutional diversity. Princeton University Press, Princeton, NJ

Ostrom E (2010) Polycentric systems for coping with collective action and global environmental change. Glob Environ Chang 20:550-557. https://doi.org/10.1016/J.GLOENVCHA.2010.07.004

Pahl-Wostl C (2009) A conceptual framework for analysing adaptive capacity and multi-level learning processes in resource governance regimes. Glob Environ Chang 19:354-365. https://doi.org/10. 1016/J.GLOENVCHA.2009.06.001

Pahl-Wostl C, Sendzimir J, Jeffrey P, Aerts J, Berkamp G, Cross K (2007) Managing change toward adaptive water management through social learning. Ecol Soc 12. https://doi.org/10.5751/ ES-02147-120230

Pittman J, Armitage D (2019) Network governance of land-sea social-ecological systems in the Lesser Antilles. Ecol Econ 157:61-70. https://doi.org/10.1016/J.ECOLECON.2018.10.013

Preston BL, Westaway RM, Yuen EJ (2011) Climate adaptation planning in practice: an evaluation of adaptation plans from three developed nations. Mitig Adapt Strateg Glob Chang 16:407-438. https://doi.org/10.1007/s11027-010-9270-x

Reckien D, Flacke J, Olazabal M, Heidrich O (2015) The influence of drivers and barriers on urban adaptation and mitigation plans - an empirical analysis of European Cities. PLoS ONE 10:e0135597. https://doi.org/10.1371/journal.pone.0135597

Roca E, Villares M (2016) La integración del cambio climático en la planificación de los riesgos ambientales en el litoral catalán. In: Olcina J, Rico A, Moltó E (Eds.), Clima, sociedad, riesgos y ordenación del territorio, vol. 10. Publicaciones de la Asociación Española de Elimatología. Serie A, pp. 595-602

Roca E, Julià-Verdaguer A, Villares M, Rosas-Casals M (2018) Applying network analysis to assess coastal risk planning. Ocean Coast Manag 162:127-136. https://doi.org/10.1016/j.ocecoaman. 2018.02.001

Rosenzweig C, Solecki W, Hammer SA, Mehrotra S (2010) Cities lead the way in climate-change action. Nature 467:909-911. https://doi.org/10.1038/467909a

Sabatier P, Focht W, ... M.L.-S. upstream, 2005, U (2005) Collaborative approaches to watershed management, in: Swimming Upstream. https://doi.org/10.7551/mitpress/6577.003.0005

Saleh F, Weinstein MP (2016) The role of nature-based infrastructure (NBI) in coastal resiliency planning: a literature review. J Environ Manage. https://doi.org/10.1016/j.jenvman.2016.09.077

Sauer I, Roca E, Villares M (2019) Beach Users' Perceptions of coastal regeneration projects as an adaptation strategy in the western Mediterranean. J Hosp Tour Res 109634801988911. https://doi.org/ $10.1177 / 1096348019889112$

Stojanovic T, Barker N (2008) Improving governance through local coastal partnerships in the UK. Geogr J 174:344-360. https://doi.org/10.1111/j.1475-4959.2008.00303.x 
Therrien MC, Jutras M, Usher S (2019) Including quality in social network analysis to foster dialogue in urban resilience and adaptation policies. Environ Sci Policy 93:1-10. https://doi.org/10.1016/j. envsci.2018.11.016

Vignola R, McDaniels TL, Scholz RW (2013) Governance structures for ecosystem-based adaptation: using policy-network analysis to identify key organizations for bridging information across scales and policy areas. Environ Sci Policy 31:71-84. https://doi.org/10.1016/J.ENVSCI.2013.03.004

Wahl T, Jain S, Bender J, Meyers SD, Luther ME (2015) Increasing risk of compound flooding from storm surge and rainfall for major US cities. Nat Clim Chang 5:1093-1097. https://doi.org/10.1038/ nclimate 2736

Young OR, Berkhout F, Gallopin GC, Janssen MA, Ostrom E, van der Leeuw S (2006) The globalization of socio-ecological systems: an agenda for scientific research. Glob Environ Chang 16:304-316. https:// doi.org/10.1016/j.gloenvcha.2006.03.004

Publisher's note Springer Nature remains neutral with regard to jurisdictional claims in published maps and institutional affiliations.

\section{Authors and Affiliations}

\section{Inga J. Sauer ${ }^{1,2}$ D Elisabet Roca ${ }^{3}$ (D) Míriam Villares $^{3}$ (D)}

Elisabet Roca

elisabet.roca@upc.edu

Míriam Villares

miriam.villares@upc.edu

1 Potsdam Institute for Climate Impact Research, Telegraphenberg A 56, 14473 Potsdam, Germany

2 Institute for Environmental Decisions, ETH Zurich, Universitätstr. 22, 8092 Zurich, Switzerland

3 Department of Civil and Environmental Engineering, Universitat Politècnica de Catalunya BarcelonaTech, Jordi Girona,1,3, Barcelona 08034, Spain 